\title{
Exploring the Moderating Effect of Interpersonal Emotion Regulation Between the Integration of Opportunity and Resource and Entrepreneurial Performance
}

\author{
Na Li', Yu Sun ${ }^{2}$, Dake Jiang ${ }^{3}$ and Xiu Yang ${ }^{4 *}$ \\ ${ }^{1}$ School of Management, Changchun University, Changchun, China, ${ }^{2}$ School of Economics and Management, Dalian \\ University of Technology, Dalian, China, ${ }^{3}$ Public Security Department, Criminal Investigation Police University of China, \\ Shenyang, China, ${ }^{4}$ Accounting and Auditing College, Guangxi University of Finance and Economics, Nanning, China
}

OPEN ACCESS

Edited by:

Marinella Coco,

Università di Catania, Italy

Reviewed by:

M. Nazmul Islam,

University of Malaya, Malaysia

Silvio Manuel da Rocha Brito, Instituto Politécnico de Tomar (IPT),

Portugal

*Correspondence:

Xiu Yang

2017110016@gxufe.edu.cn

Specialty section: This article was submitted to

Organizational Psychology,

a section of the journal

Frontiers in Psychology

Received: 12 August 2021 Accepted: 04 October 2021 Published: 28 October 2021

Citation:

Li N, Sun Y, Jiang $D$ and

Yang $X$ (2021) Exploring the

Moderating Effect of Interpersonal Emotion Regulation Between the Integration of Opportunity and

Resource and Entrepreneurial

Performance.

Front. Psychol. 12:756767.

doi: 10.3389/fpsyg.2021.756767
This study explains how start-ups obtain a high accumulated performance by aligning and employing an integration between opportunities and resources (IOR) in a dynamic environment and whether these potential benefits are associated with interpersonal emotion regulation. Using 274 enterprise samples, the findings confirm that an IOR has a significant positive effect on entrepreneurial performance. In addition, positive emotion and interpersonal relationship regulation positively moderate the relationship between IOR and entrepreneurial performance. This paper proposes a new concept of the IOR and measures it for the first time. Then, the relationship was explored between the IOR, interpersonal emotion regulation, and entrepreneurial performance. This research not only systematically integrates opportunities and resources and avoids their separation but also helps to reveal the context of entrepreneurship research, enrich entrepreneurship theory, and expand the boundaries.

Keywords: opportunity, resource, interpersonal emotion regulation, entrepreneurial performance, entrepreneurship

\section{INTRODUCTION}

Tremendous institutional and economic transitions are experienced by developing countries. Institutions and markets are highly uncertain in a transitional economy (Huang et al., 2015; Gao et al., 2018). Incomplete institutional structures and the unbalanced development of subsistence markets create tremendous risks for start-ups (Tan, 2001), although Chinese policy encourages the "masses to start their own businesses and to make innovations." In particular, scarce resources are unfairly distributed due to the excessive interference of local administrations, and opportunities tend to be instantaneous due to the fuzzy boundary of subsistence markets and the fast pace of the competitive structure (Walder, 1995; Davcik and Sharma, 2016; Ge et al., 2018). This situation creates new challenges for start-up development: how can start-ups achieve high cumulative performance when coordinating opportunities and resources in a dynamic environment and are the potential benefits associated with interpersonal emotion regulation. The answers to these questions have substantial practical 
significance for assisting start-ups in effectively breaking through the restrictions of resource constraints and creating relevant opportunities to maximize their value in a dynamic and uncertain environment. It is highly valuable to explore the causal linkages between opportunities and resources in developing countries.

Opportunities and resources orientations in the dualistic theory of entrepreneurship are prominent in entrepreneurial research. In fact, opportunities and resources are mutually reinforcing and concomitant relations. However, the existing research mainly focuses on the single role of opportunities or resources and lacks the research from the perspective of integration (Teece, 2007; Sirmon et al., 2011). Further clarification is required to determine whether the complementary effect between opportunities and resources works well in a transitional economy and whether effective interpersonal emotion regulation promotes such efficiency. It is necessary to establish a theoretical model of integrating opportunities and resources from the perspective of system theory and to clarify its correlation with entrepreneurial performance.

Therefore, this study answers questions about how start-ups obtain a high accumulated performance by aligning opportunities and resources and employing integration between opportunities and resources (IOR) in a dynamic environment and whether these potential benefits are associated with interpersonal emotion regulation. This study is based on these ideas and guided by the maxims of the traditional Chinese philosophies of "the balance of yin and yang" and "the cultivation of both the internal and the external." Therefore, first, we divide the IOR into two subdimensions, internal and external integration, and measure them. Ultimately, the IOR will also reflect their interaction and balance. Briefly, the paper explores the relationships between internal and external integration, the IOR, and entrepreneurial performance. Concurrently, we validate the moderating effects of positive emotion and interpersonal relationship regulation on the IOR and entrepreneurial performance.

Using 274 enterprise samples, we find that the entrepreneurial performance of start-ups in developing countries is optimal when internal and external integration are available at a collectively high level. Internal integration creates opportunities by piecing together existing resources. However, external integration is also required as opportunity discovery to cover shortages. That is, external integration has a complementary effect on internal integration. However, internal integration is essential to external integration. When faced with the resource constraints caused by fierce market competition, the auxiliary function of internal integration is necessary. In short, the IOR represents a high level of internal and external integration, and the two concepts can compensate for each other's deficiencies so entrepreneurial efforts can perform highly in a transitional economy.

In addition, the results demonstrated that interpersonal emotion and relationship regulation further maximize the benefits of the IOR in social processes outside corporate boundaries. They also elucidated that interpersonal emotion regulation is not a negligible element in a transitional economy.
For example, positive emotion regulation can enhance the cognitive flexibility of team members, stimulate them to discover further similarities or differences, and promote the integration of new and existing knowledge, which results in continuous competition for resources to the organization. In addition, interpersonal emotion regulation enhances team identity and trust by forming good interpersonal relationships between team members, thereby achieving cooperation and social promotion. Therefore, interpersonal emotion regulation can nurture incrementally fruitful performance benefits in the IOR.

This observation provides enlightenment for entrepreneurial start-ups in developing countries. First, the synergies of internal and external integration allow the returns of enterprises to outperform those in situations in which the two factors are separated. To ultimately capture such benefits, entrepreneurs must design strategies to significantly align internal and external integration. Second, entrepreneurial start-ups are inclined to effectively carry out interpersonal emotion regulation activities that can expand their gains in a turbulent system and a dynamic competitive market. Therefore, we encourage entrepreneurs to build positive team emotion and harmonious interpersonal relationships to obtain higher returns. This effort requires enterprises to pay attention to the training of identifying leaders' tendencies and abilities in terms of interpersonal emotion regulation from the perspective of leaders' development plans and improve and construct their effective strategies.

\section{THEORETICAL BACKGROUND AND HYPOTHESES}

\section{Internal and External Integration, the IOR, and Entrepreneurial Performance}

The core of entrepreneurial research is the matching of opportunities and resources. How to coordinate the two is the key to entrepreneurial success. Especially in the uncertain environment, it is more important to properly deal with the relationship between opportunities and resources. Only by comprehensively balancing opportunities and resources can achieve high performance. Leaning on either side of opportunities and resources will affect the effectiveness of entrepreneurial activities. Therefore, in the process of the interaction between opportunities and resources, the systematic integration of opportunities and resources has been advocated by scholars. This can not only avoid the one-sidedness of research, but also explore the essential process of entrepreneurship. On this basis, scholars further construct a theoretical system of opportunity and resource integration development behavior from the perspective of system theory and reveal the symbiotic evolutionary mechanism of the two. In recent years, the research results have gradually been enriched on the integrated exploitation of opportunities and resources. Clarifying the complex relationship between opportunities and resources and solving their "fragmented" situation are the origin of the IOR concept. This paper combines the conceptual design of the opportunity development process by Shane and Venkataraman (2000), the 
definition of resource development type by Brown et al. (2001), the systematic classification of the connotation between "opportunities under resources" and "resources under opportunities" by Ge et al. (2016), and the idea of merging opportunities and resources by Bhuian et al. (2005) and Boso et al. (2013). On these bases, this paper demarcates "internal and external resources" and combines the interaction between them into two parts, internal and external integration (see Figure 1).

First, the classification principle is based on the theory of ying-yang balance, a philosophy of dialectical materialism. The ying-yang balance shows that the existence and development of all things contain two factors that are opposite but reciprocal. The opposition between the yin and the yang is not absolute and static but relative and active. The ying-yang balance needs to be preserved and not neglected (Li, 2012). The ying-yang balance can direct the development of all things and is applicable to start-ups. In this paper, both internal and external integration are separated on account of two different resources, the internal and the external. Internal integration tends to elevate firms by creating opportunities according to "pieced-together internal resources" and capturing opportunities by "integrating the internal resources" of the moment, i.e., when opportunities are created within the firm and the resources used for creating these opportunities are derived from the firm (Lumpkin and Dess, 1996). External integration, however, emphasizes the decisive power outside the firm, especially the importance of identifying and acquiring external resources. When external integration works, firms tend to discover opportunities and utilize external resources. Therefore, internal and external integration are the two main modules of the entrepreneurial system. Although one is the yin and the other is the yang, they do not cross (Wiklund and Shepherd, 2003). However, only when they work together can they balance the entrepreneurial system, of which both are indispensable.

Second, internal and external integration are effective. Internal integration includes two subdimensions: identifying resources and opportunities and assigning resources while utilizing opportunities. The former represents the creation of opportunities by piecing together existing resources, while the latter represents the exploration of opportunities by integrating existing resources as a precondition. The patchwork of entrepreneurship was formally proposed by Baker and Nelson (2005) whose study found that "creating something out of nothing" was the most effective means of breaking the constraints of resource shortages for new firms; furthermore, the new value it creates is unique. Because new firms have inherent weaknesses, the inflows of external resources are limited. Consequently, it is both a challenge and an opportunity for new firms to selectively combine fragmented and neglected resources, with some resources mistakenly being considered worthless. Senyard et al. (2009) also noted that the patchwork of entrepreneurship has a significant role in promoting the financial and growth performance of new businesses. However, at the same time, the important role should not be overlooked of resource integration for internal integration (Cheng and Huizingh, 2014; Ma and Huang, 2016). Under the guidance of resource-based theory, Hitt et al. (2003) clearly emphasized that, as a driving force for developing opportunity, resource integration can promote strategic flexibility and performance in a new enterprise. Finally, the theory proposes

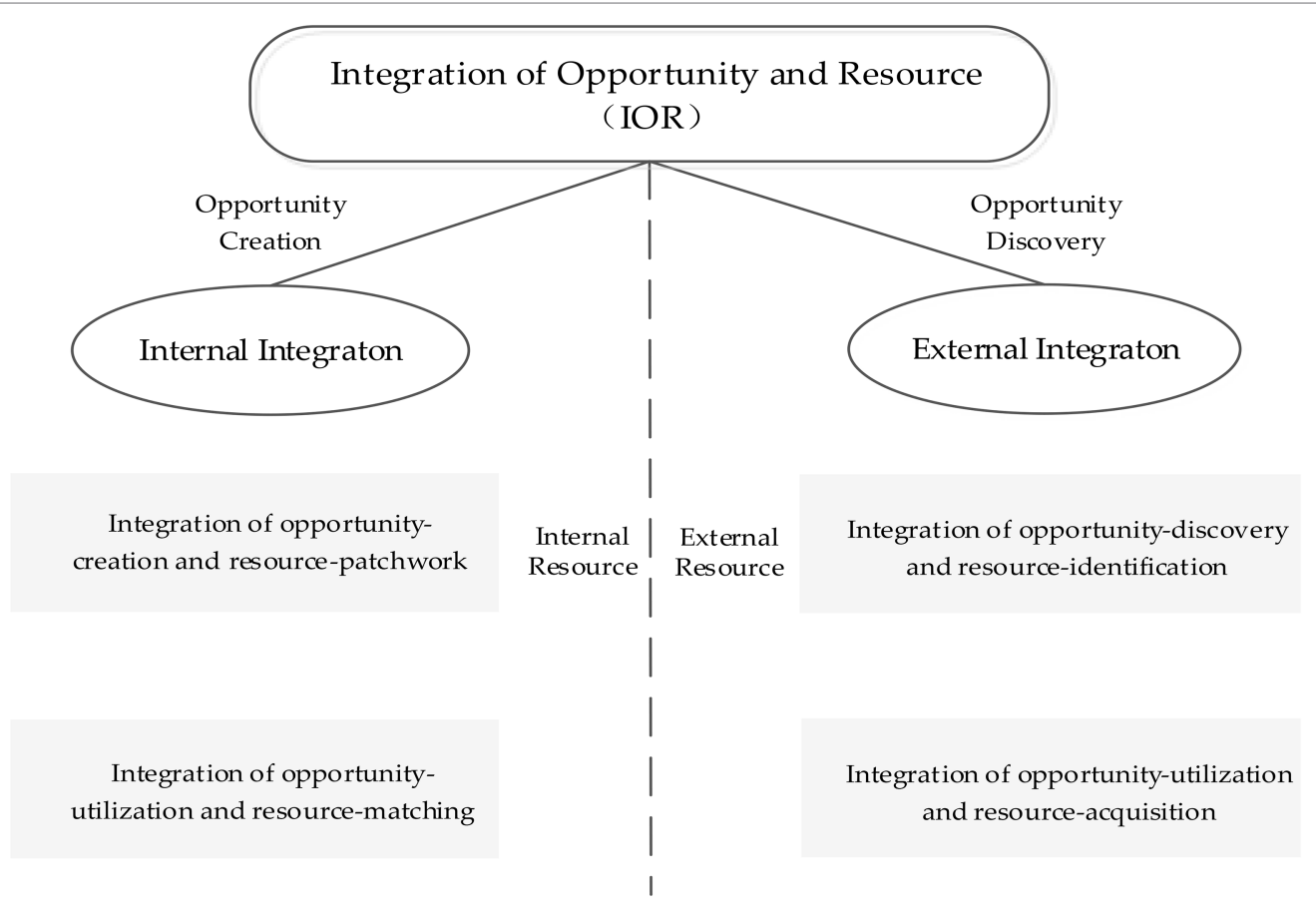

FIGURE 1 | The model of the integration of opportunity and resource. 
the chain of resource integration-strategic flexibility-opportunity development-performance. Sirmon et al. (2011) and Teece (2007) recognized that resource integration, the ultimate method for simultaneously achieving internal consistency among resources and strategies, improves the ability to respond to environmental uncertainty and resolve the problems of facing ambiguous opportunities. Therefore, resource integration can cultivate a solid competitive advantage for enterprises. Clearly, when internal integration works, opportunities may be derived from resources, and the subsequent value of the opportunities depends on resources as well. Briefly, internal integration can promote the performance of new businesses.

\section{Hypothesis 1: Internal integration is positively related to} entrepreneurial performance.

Different from internal integration, external integration includes two other subdimensions: the combination of opportunity and resource identification and that of opportunity utilization and resource acquisition. The core of the former lies in identifying opportunities in dynamic environments that include uncertain market demand, massive amounts of data, large industrial trends, unique resource structures, and business models. Identifying opportunities is one of the main aspects of external integration. In fact, from the perspective of scholars taking opportunities as the primary goal, identifying opportunities is the core of entrepreneurship. Alvarez and Busenitz (2001) pointed out that opportunity identification is a source of competitive advantage for new firms and a basic precondition for bringing innovative goods and services to a market. Furthermore, effective opportunity identification allows companies to gain unimaginable profits (Baron, 2006; Bakker and Shepherd, 2017). However, enterprises must pay attention to the value of resources in this process, especially the value of knowledge resources. Obtaining more opportunities, however, does not equate to owning more innovative opportunities, nor does it represent the opportunities that can create higher value (Zahra et al., 2005; Petti and Zhang, 2011). Only a higher level of prior knowledge can identify more valuable opportunities. Therefore, the integration of opportunity and resource identification has a positive effect on new firm performance. However, the relationship between opportunity identification and performance is not linear. In regard to the integration of opportunity utilization and resource acquisition, effective access to external resources - such as financing, loans, government policies, support from partners, partnerships with suppliers, and a good reputation from customers - can significantly promote new firm performance.

Hypothesis 2: External integration is positively related to entrepreneurial performance.

Finally, internal and external integration are not integral. Similar to the mutual promotion and restraint of the yin and yang, the opposition between the two growth models (internal and external integration) is not absolute. Therefore, "the cultivation of both internal and external" integration is crucial for start-ups (Ennen and Richter, 2010; Song et al., 2010). For internal integration, combining the piecing together of resources with the recognizing of opportunities develops new opportunities - creative ones - with extremely limited resources. However, for external integration, the combination of opportunity and resource identification leads to new discovery opportunities in an uncertain environment. An opportunity type can be easily overlooked within a single kind of growth model. Similarly, regarding the combination of assigning resources and utilizing opportunities, one model of internal integration, collecting internal resources, can affect the outcome of exploiting opportunities, certainly in terms of enriching resources and enhancing stability, but also by neglecting the role of new resources outside the firm. Two key external and institutional factors - especially in China, which suffer from a transitional economy - imply multiple hidden resources, which are frequently fatal to firm success (Samuelsson and Davidsson, 2009). Therefore, although internal and external integration are opposed, they promote each other. The IOR reflects a balanced and reciprocal mechanism between them, namely, they interact. Therefore, the study proposes the third hypothesis:

\section{Hypothesis 3: The IOR is positively related to entrepreneurial performance.}

\section{IOR, Interpersonal Emotion Regulation, and Entrepreneurial Performance}

In recent years, an increasing number of researchers have paid attention to emotion research in the field of organizational behavior. Emotion plays an important role in individual work outputs, team interactions, organizational decision-making, and reforms. Emotion has an important impact on many processes and results to which managers pay attention, such as conflict, cooperation, creativity, etc. Therefore, this paper discusses the impact of the IOR on entrepreneurial performance from the perspective of emotional regulation. Since China's economy is transitional, both the institution and market are highly uncertain. In this context, social integration contributes to the realization of the firm's new idea of constructive relationships among group members - manifested in aspects, such as cohesion, collaboration, and interpersonal facilitation (West, 2002; Hulsheger et al., 2009) - as well as in the influence of shared feelings within the team on social integration (Keltner and Haidt, 1999). Because entrepreneurship is an interpersonal process, the organization is an aggregation of emotional resources based on motivation, learning, and change. When an organization uses emotional ability to integrate and guide its internal emotion (Huy, 1999), it not only needs to be supported by strategic tools, such as selection, representation, and training but also needs to strictly conform to the organizational value level to achieve consistency and matching between organizational emotion and strategic actions. Emotion, particularly positive emotion, is the driving force of employee performance (i.e., emotions with positive values) and can promote a range of performance-related behaviors in the workplace (Rothbard and Wilk, 2011). For roles such as those played by supervisors 
and mentors who are responsible for improving the task performance of others (e.g., team members and clients), strategically improving the positive emotion of others may be an important means of improving their task performance (Niven, 2016). One way to improve the positive emotion of others is to use interpersonal affective regulation, which is intended to consciously initiate, maintain, or modify the occurrence, intensity, or duration of other people's emotions (Niven et al., 2009). In short, interpersonal emotion regulation is effective for start-ups who must deal with the uncertainty of China's transitional economy.

Based on the emotion regulation process model theory proposed by Little et al. (2012), the interpersonal emotion measurement tool proposed by Holman and Niven (2019) divides the regulation strategies into four categories: cognitive reappraisal, attentional deployment, situation modification, and relational engagement. Cognitive reappraisal attempts to influence the emotions of others by expressing and changing their cognition. Attentional deployment intends to focus or divert attention away from troublesome problems. These two strategies focus on the positive emotions of others, which are summarized as positive emotion regulation in this paper. Situation modification is defined as changing the situation to modify the influence on the emotions of others. Relational engagement is more concerned with relationships with others. These two strategies belong to interpersonal relationship regulation. By disentangling the question of whether the synergistic effects of opportunities and resources on entrepreneurial performance are restricted by levels of interpersonal emotion regulation in developing markets, this work extends the entrepreneurial performance created by high levels of IOR.

According to feeling-as-information theory and broadenand-build theory of positive emotion, positive emotion has two functions: expansion and construction. That is, positive emotion can expand the basic cognition, thinking, and action categories of individuals; promote individuals in breaking through established limits; and produce more valuable thoughts. In addition, positive emotion can promote individuals to build cognitive, social, and other resources and provide sustainable resources for their growth (Fredrickson, 2001). When enthusiasm and activity ability are improved, existing behavior habits will be improved accordingly so a series of performance-related behaviors can be improved (Fredrickson and Branigan, 2005). Especially when an organization is faced with creative tasks and important decisions, such as internal and external integration actions, positive emotion can enhance the cognitive flexibility of team members, motivate them to find more similarities or differences between things, connect and integrate different information (Isen, 2000), and quickly make more thorough and effective choices. Moreover, in terms of attention, positive emotion can expand the visual search pattern, especially in the visual domain of peripheral stimuli, and can update individuals' mental representations of the environment (Friedman and Forster, 2010). By promoting the integration of new and the existing knowledge, positive emotion can help to establish a long-term task knowledge system and make it easier to generate and implement creative ideas, which can more effectively transform cognition into high-quality performance (Konradt et al., 2003). In the process of external integration, a variety of uncertain problems can easily be solved innovatively, and it is no longer difficult for enterprises to create new products and new things. This situation may result in continuous competition for resources for the organization and improve organizational performance. Therefore, positive emotion regulation can affect the significance level of the relationship between the IOR and entrepreneurial performance. Accordingly, we hypothesize the following.

Hypothesis 4: The IOR is more positively related to entrepreneurial performance when positive emotion regulation is higher.

The second strategy of interpersonal emotion regulation is interpersonal relationship regulation. Compared with directly regulating individuals' positive emotion, this strategy forms a positive emotional tone and good interaction and cooperation within the entrepreneurial team by forming a good interpersonal relationship among team members (Knight and Eisenkraft, 2015), which has an important impact on internal and external integration and entrepreneurial performance. During contextual modification and relational engagement, leaders remove, modify, or change situations and focus on improving team relationships. For example, if employees are anxious about completing work within a given time, supervisors may change the situation by reducing the amount of work required for the task or reassigning some responsibilities to others. The transmission of interpersonal care helps employees reevaluate the event so they can change the situation to modify its emotional impact (Niven et al., 2012) and further strengthen the benign group interaction norms and identity. Team identity enhances team cohesion, willingness to cooperate, and trust and moderates the sense of a shared vision, making the team more flexible and adaptable (Langfred, 2007). Entrepreneurial team members are highly interdependent because they share a goal, and they identify and develop opportunities together. Enterprises with good interpersonal adjustment ability perform better than their competitors do. In a turbulent market, entrepreneurial team members form a highly interdependent relationship because they share a goal. With different abilities, good communication and cooperation can produce cooperation effects, and employees can together identify and develop opportunities and integrate internal and external resources. Whether times are good or bad, employees can fully trust and encourage each other. In addition, in the complex and changeable entrepreneurial environment, relying on trust, high-quality information, and tacit knowledge that is effectively transferred, team members can efficiently learn and rapidly improve their innovation ability. This process effectively integrates heterogeneous knowledge resources and contributes to the improvement of entrepreneurial performance. Therefore, interpersonal relationship regulation can enhance the integration of opportunities and resources and cause the two strategies to concurrently promote each other, thus improving entrepreneurial performance. 
Hypothesis 5: IOR is more positively related to entrepreneurial performance when interpersonal relationship regulation is higher.

Figure 2 presents the overall framework of this research.

\section{METHODOLOGY}

\section{Data Gathering and Sample}

In this study, to test the proposed hypotheses, we prepared a questionnaire that has not been published previously. Samples (291 firms) were identified from the China Small and Medium Enterprises Statistical Yearbook and the National Small and Medium-sized Enterprises Big Data Platform, both of which provide detailed information about medium-sized enterprises. Samples were then screened, and new enterprises of less than 8 years old were used as the research objects. We invited senior and intermediate managers from alternative enterprises to be our informants using contact information from their companies' websites because they receive global information about their company. This fact makes them valuable sources for evaluating each organization's variables. To ensure that our sample can represent a larger population, first, the research areas included Beijing, Shanghai, Changchun, Shenyang, Hangzhou, and Shenzhen. These cities have different levels of development, including well-developed central cities and economically inactive cities in the north as well as southern coastal cities whose economies are thriving. Therefore, this study avoided the influence of regional economic development. Second, we chose informants who worked in start-ups of different industries when collecting data. Finally, we chose informants of different ages, ranging from 18 to 62 years.

Simultaneously, we utilized different investigation methods, including email messages and face-to-face conversations but the same questionnaires to collect data. Before the investigation, we promised participants that the detailed information they provided about their companies would remain confidential. Additionally, we clarified in the questionnaires that we would continue the investigation only when the informant agreed. The data-collection process lasted for 10 months, from November 2019 to September 2020. The data collection was mainly divided into three channels. First, after telephone appointments with managers, we collected 78 valid questionnaires through a survey of enterprises via face-to-face questionnaires completed by managers, without any invalid questionnaires. Second, focusing on the distribution of EMBA students, who were all middle or top managers, we collected 94 valid and six invalid questionnaires (those omitting fill-in items). Third, we distributed the questionnaires by email, collecting 113 questionnaires, excluding 11 invalid ones (which were completed in less than $5 \mathrm{~min}$ ), and retaining 102 high-quality ones. To ensure the questionnaire quality, we excluded those completed in less than $5 \mathrm{~min}$ and those with missing items. Finally, 274 high-quality and effective questionnaires were collected. Third, the characteristics of responding businesses were compared to those of the nonresponding ones to reduce the possibility of nonresponse bias. We carried out a $\mathrm{T}$ test on the control

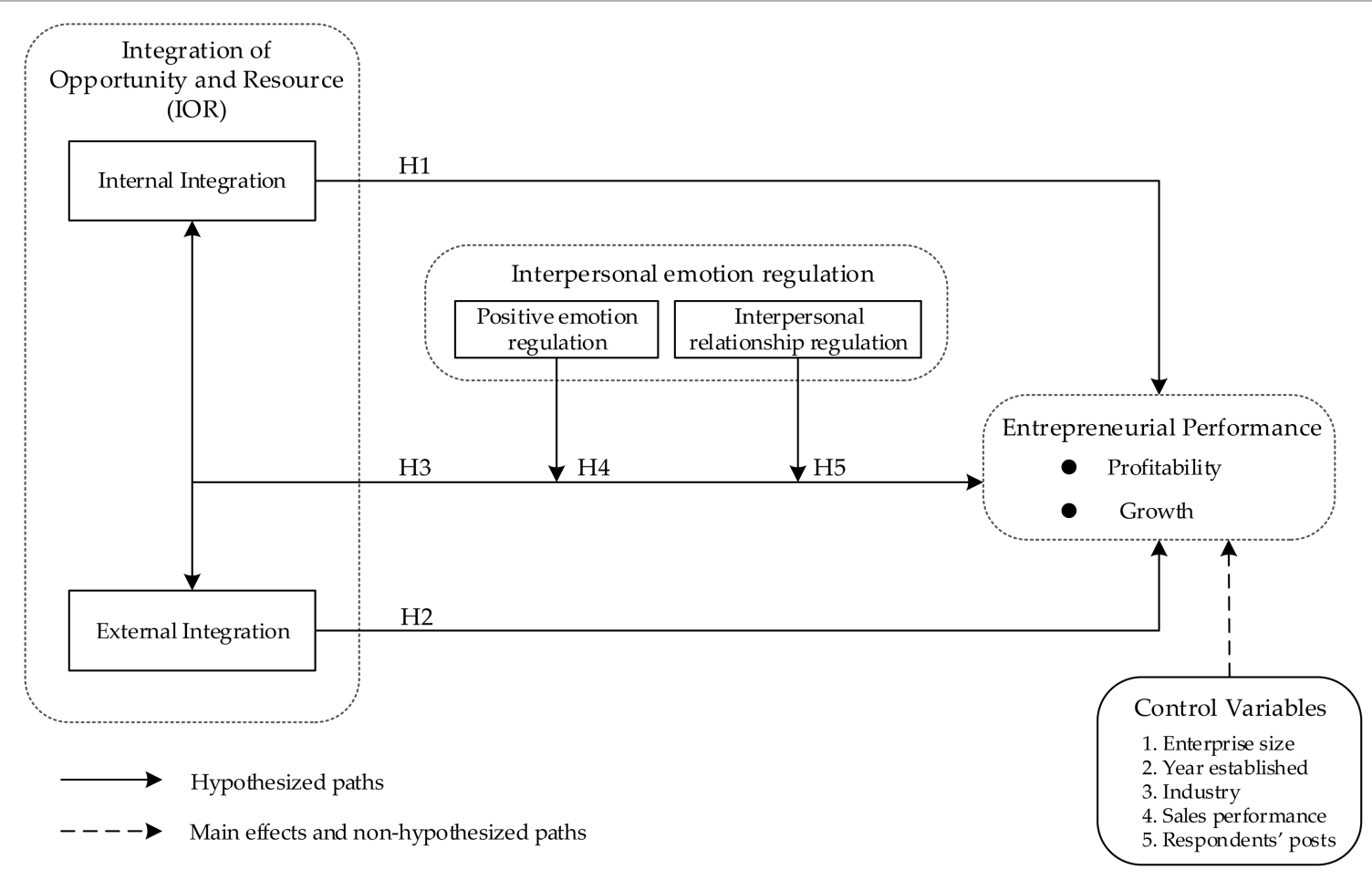

FIGURE 2 | The research model. 
variables, and the results for invalid and valid results indicated no significant difference between the respondents and the nonrespondents (refer Table 1).

\section{Variable Measurements}

Based on the hypotheses, the following section lists the required measurement items of this paper. We invited a professional scholar, an industry entrepreneur, and a representative from a government department to test the questionnaires to guarantee the scientific nature of these issues. We made some minor adjustments based on their recommendations to avoid misunderstanding the respondents. All the items were measured at five levels, where " 1 " represented a very insignificant description of the actual situation of the respondents and " 5 " was extremely consistent.

The IOR was the independent variable, which was reflected by the synergies between internal and external integration. Internal integration includes the integration of opportunity creation and resource patchwork and that of opportunity utilization and resource matching. We used four items that principally come from Baker and Nelson (2005) and Alvarez and Busenitz (2001) to measure the former and five items coming from Sarasvathy (2009) to measure the latter. External integration includes the integration of opportunity discovery and resource identification and that of opportunity utilization and resource acquisition. The three measurements of the former were mainly based on the research of Casson and Wadeson (2007) and Shepherd and Detienne (2005). The other five measurements of the latter were mainly based on the research of Timmons et al. (1994). Interpersonal emotion regulation, which consisted of positive emotion and interpersonal relationship regulation, was the mediating variable. The study utilized six items that principally came from Holman and Niven (2019) to measure interpersonal emotion regulation. The dependent variable was entrepreneurial performance, which includes profitability and growth. Because the scale measuring entrepreneurial performance is well developed, this study used six items to measure entrepreneurial performance. This paper applied as control variables enterprise size, the year the firm was established, the industry to which the company belongs, the average turnover level in the past 3 years and the respondent posts pertaining to the enterprise (Zahra, 2012).

\section{Reliability Test and Factor Analysis}

Table 2 displays the reliability and validity of the test results regarding internal and external integration, interpersonal emotion regulation, and entrepreneurial performance. We employed Cronbach's $\alpha$ coefficient tests on the reliability of the scale and applied the variance contribution rate of the first principal component to test the scale validity. Better validity generally requires a variance contribution rate of $60 \%$. The $\alpha$ coefficient of each variable was greater than 0.85 , which was an acceptable level of reliability. The variance contribution rate of the first principal component of each variable was higher than $70 \%$. Moreover, the factor loads of most items were greater than 0.8 , revealing relatively high validity. Therefore, the scale employed in the study was reliable and valid (refer to Table 2).

In order to verify whether the distribution of variables conforms to the normality, this paper also uses the method of normality moment to test the skewness and kurtosis of IOR, interpersonal emotion regulation, and entrepreneurial performance. The results show that the skewness coefficient of IOR is 0.250 and the kurtosis coefficient is 0.383 . The skewness coefficient of interpersonal emotion regulation is 0.078 and the kurtosis coefficient is -0.509 . The skewness coefficient of entrepreneurial performance is 0.034 and the kurtosis coefficient is -0.15 . The results show that the variables in this study correspond to normal distribution.

In addition, Harman's single-factor test was used for the common method variance (CMV) test. A principal component analysis was conducted for all the questions in the sample questionnaire, and the table of "total variance explanation"

TABLE 1 | Characteristics of survey samples.

\begin{tabular}{|c|c|c|c|c|c|c|c|}
\hline \multirow{2}{*}{$\begin{array}{l}\text { Enterprise size } \\
\text { 1-10 people }\end{array}$} & \multirow[b]{2}{*}{17.8} & \multicolumn{2}{|c|}{ Year established } & \multicolumn{2}{|c|}{ Average turnover level in recent 3 years } & \multicolumn{2}{|c|}{ Age } \\
\hline & & 1 year or less & 7.1 & Half a million or less & 22.7 & $18-28$ & 8.8 \\
\hline $11-50$ people & 23.4 & & & Half a million to 1 million & 11.1 & 29-39 & 48.5 \\
\hline 51-100 people & 13.8 & $1-3$ years & 18.6 & 1-2 million & 5.9 & $40-50$ & 24.8 \\
\hline 101-300 people & 19.3 & $3-5$ years & 27.1 & 2-3 million & 7.1 & $51-61$ & 10.2 \\
\hline More than 300 people & 25.7 & $5-8$ years & 47.2 & $\begin{array}{l}3-5 \text { million } \\
\text { More than } 5 \text { million }\end{array}$ & $\begin{array}{r}9.7 \\
43.5\end{array}$ & 62 or above & 7.7 \\
\hline \multicolumn{3}{|c|}{ Industry } & \multicolumn{3}{|c|}{ Posts of respondents } & \multicolumn{2}{|c|}{ Research area } \\
\hline $\begin{array}{l}\text { Software and } \\
\text { communications }\end{array}$ & 17.1 & $\begin{array}{l}\text { Transportation, } \\
\text { storage and rent }\end{array}$ & 13.7 & State-owned & 14.5 & Shenyang & 11.3 \\
\hline Manufacturing & 17.8 & & & Foreign & & Changchun & 31.0 \\
\hline Real estate & 7.0 & $\begin{array}{l}\text { Transportation, } \\
\text { storage and rent }\end{array}$ & 5.9 & investment & 5.6 & Beijing & 15.0 \\
\hline $\begin{array}{l}\text { Energy and environmental } \\
\text { protection }\end{array}$ & 2.9 & $\begin{array}{l}\text { Accommodation } \\
\text { and catering }\end{array}$ & 34.9 & Private & 70.2 & Shenzhen & 15.0 \\
\hline \multirow[t]{2}{*}{ Finance } & 0.7 & & & Joint venture & 9.7 & Hangzhou & 13.5 \\
\hline & & & & & & Shanghai & 14.2 \\
\hline
\end{tabular}

All figures in the table are percentages (\%). 
TABLE 2 | Results of the reliability and validity test.

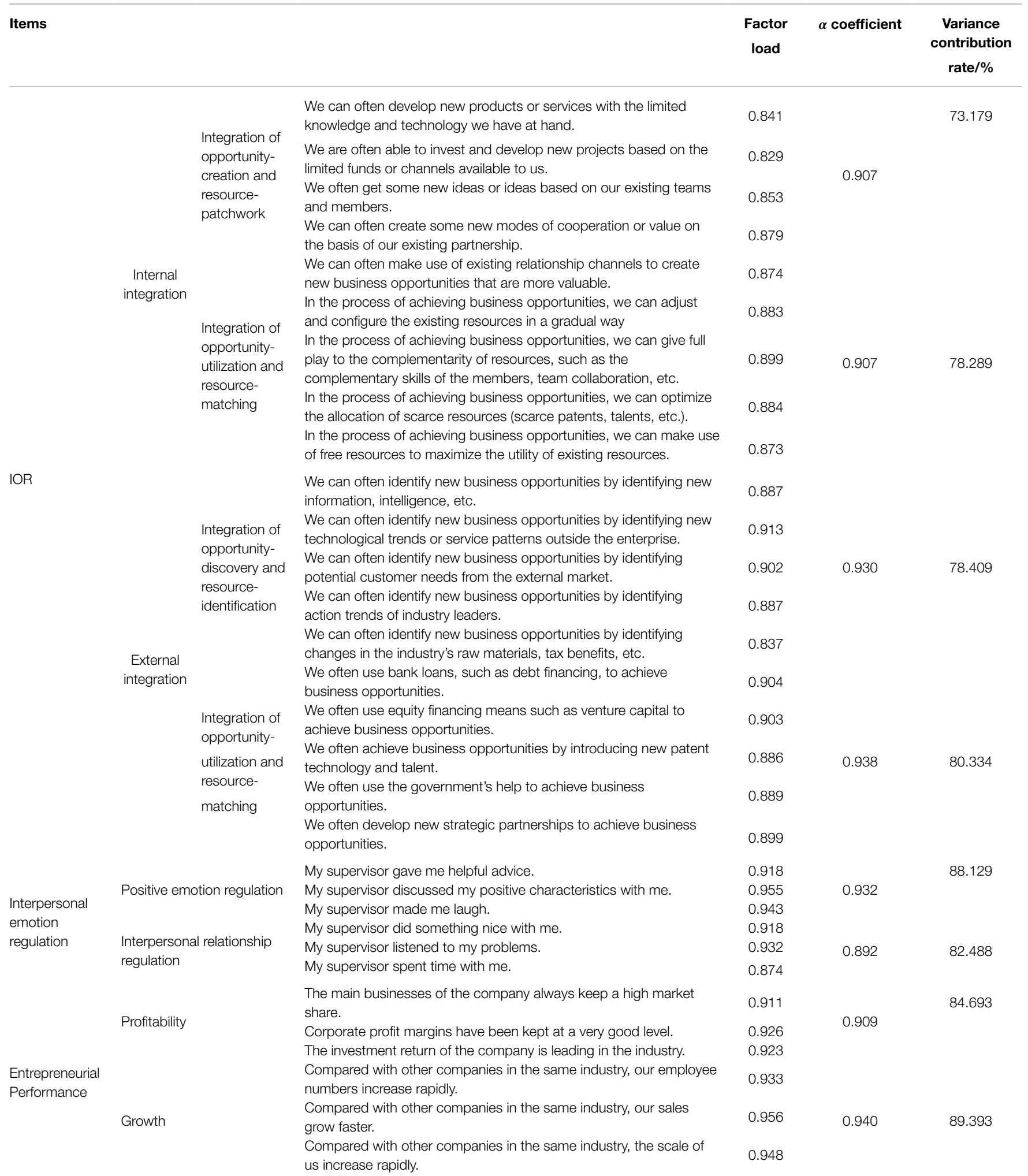

was checked in the output results. The eigenvalue before rotation was greater than 1 as the judgment criterion. Furthermore, if the explanatory variation of the first factor is less than $50 \%$, it is considered that there was no serious CMV (Fuller et al.,
2016), and the test result of this study was $36.76 \%$. However, considering the limitations of Harman's single-factor test, this study introduced method factors to further test the CMV of the scale. Based on the CFA model in this study, the method 
factors were added as the overall factors to establish the two-factor model, and the change was observed in the fitting degree of the overall model (Podsakoff et al., 2003; Williams and McGonagle, 2016). AMOS software was used for the calculations to determine that after adding the method factors to the original CFA model, the CFI and TLI were increased by 0.092 and 0.096 (both less than 0.1 ), respectively, and the RMSEA was reduced by 0.029 (less than 0.05). The model fitting index did not improve significantly, indicating that there was no serious common method deviation.

\section{RESULTS}

\section{Descriptive Statistics and Correlation Coefficients}

Table 3 delineates the descriptive statistical results of each variable and the correlation coefficient matrix. As shown in Table 3, the mean value of the variable varied from 2 to 4 , and the SD was relatively low, which indicated that the fluctuation range of the variable was within a reasonable range. Internal and external integration were positively correlated with entrepreneurial performance, and positive emotion and interpersonal relationship regulation were positively related to entrepreneurial performance, which was consistent with the logic of the theoretical hypotheses. In addition, the enterprise size, firm establishment year, firm industry, sales performance level in the most recent 3 years, and respondents' posts were used as the five control variables in the test model. Direct and indirect interferences with the dependent variable were effectively avoided by controlling for these variables.

\section{Multivariate Linear Regression Model and Results}

Table 4 lists the results of the four multivariate linear regression models of the combination of internal and external integration, interpersonal emotion regulation, and entrepreneurial performance. The variance inflation factor (VIF) of each regression model was less than 10 , which indicated that the method avoids multicollinearity. Model 1 was the benchmark model that tested the relationship between the control variables and the dependent variable (entrepreneurial performance). Model 1 indicated that enterprise size was significantly positively related to entrepreneurial performance, indicating that a larger enterprise results in higher entrepreneurial performance. However, the firm establishment year was positively correlated with entrepreneurial performance, suggesting that older companies had lower entrepreneurial performance. Model 2 examined the pathway pertaining to the influence of internal and external integration and positive emotion and interpersonal relationship regulation on entrepreneurial performance. The regression results of Model 2 showed that internal and external integration and interpersonal relationship regulation were significantly correlated with entrepreneurial performance. In this model, a one-point SD increase in internal integration caused a
$58.8 \%$ change in profitability and a $52.2 \%$ change in growth. Furthermore, a one-point SD increase in external integration caused a $23.8 \%$ change in profitability and a $32.9 \%$ change in growth. This result emphasized that enterprises employing as their strategy internal or external integration secured better entrepreneurial performance and acquired the full advantages of interpersonal relationship regulation. The interactions between the respective variables were illustrated in Model 3. Model 4 revealed a positive interaction between internal and external integration and entrepreneurial performance, thus verifying Hypotheses 1 and 2. Compared to the results of Model 2, the combination of internal and external integration led to higher entrepreneurial performance, which validated Hypothesis 3. In Equations (1) and (2), a one-point SD increase in internal integration caused a $55.1 \%$ change in profitability and a $57.8 \%$ change in growth. Furthermore, a one-point SD increase in external integration caused a $40.1 \%$ change in profitability and a $63 \%$ change in growth. Compared with the results in Models 2 and 3, Model 4 contained the synergies of the combination of internal and external integration and positive emotion and interpersonal relationship regulation; consequently, the performance was higher. Therefore, internal and external integration and positive emotion regulation were significantly positively correlated with entrepreneurial performance, proving that excellent positive emotion regulation further promoted the positive synergies of the integration of internal and external integration on entrepreneurial performance. In addition, their internal and external integration, interpersonal relationship regulation, and entrepreneurial performance were positively correlated illustrating that preeminent interpersonal relationship regulation further improved the significant effect of the combination of internal and external integration on entrepreneurial performance. Therefore, Hypotheses 4 and 5 were verified.

These analyses indicated that the empirical results supported the aforementioned theoretical expectations, and Hypotheses 1-5 were verified. The combination of internal and external integration promoted entrepreneurial performance, and interpersonal emotion regulation played a positive role (refer to Table 4).

\section{DISCUSSION}

Since the entrepreneurship literature has focused on the matching of opportunities and resources, there has been a gap in their integration. Neither opportunity- nor resourceoriented theory breaks through the limitation of a single perspective, and studies from the integration perspective are very rare. Based on the existing theoretical gap, for the first time, we regard opportunities and resources from a holistic perspective and propose the concept of the integration of opportunities and resources (IOR). On this basis, the research explored the relationship among the IOR, interpersonal emotion regulation, and entrepreneurial performance, and all results are shown in Figure 3. In this context, our study contributes to both theory and practice. 


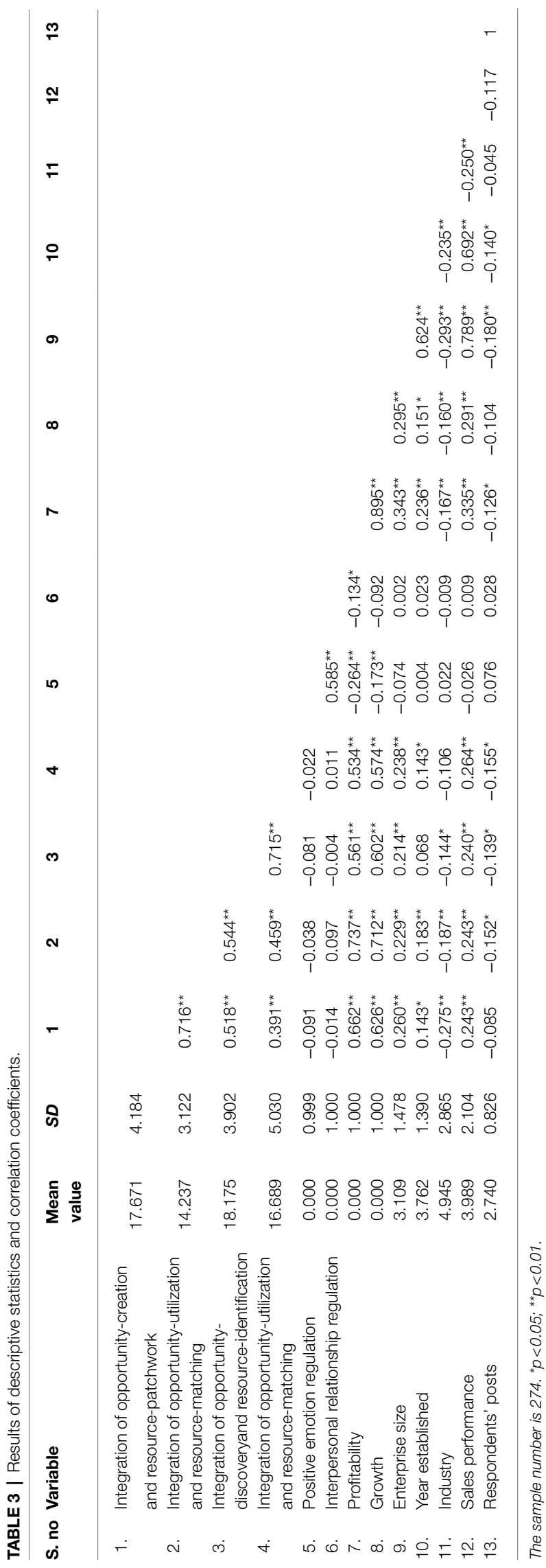

\section{Theoretical Implications}

First, the study overcomes the limitations of the unitary perspective of the dualistic theory of entrepreneurship, whose purpose is exploring the synergies of opportunities and resources, revealing the relationship between them. The application of system theory can not only help to reveal the main context of entrepreneurship, and but also can transform the entire discipline of entrepreneurship into a more scientific category. Therefore, the proposal of system theory provides a new research perspective for entrepreneurship. The system composed of opportunities and resources can deal with uncertain risks more stably in entrepreneurial research, and promote entrepreneurial performance more stably and comprehensively. The interaction and integration between opportunities and resources is a systematic process, which is complex, dynamic, multi-level, and multi-dimensional. IOR is the core and driving force of entrepreneurship.

Second, the study shows a complementary effect between internal and external integration, which are not independent concepts. Entrepreneurial performance will be higher when enterprises engage in IOR behavior. Creating opportunities is a precondition of internal integration, which unifies of opportunities and resources by piecing together and assigning internal resources. Internal integration focuses on the entrepreneurial process within an organization and advocates that opportunities are created internally and their value can be maximized by exploiting the limited resources at hand. Taking as a prerequisite opportunity discovery, external integration develops opportunities by identifying and acquiring external resources. External integration focuses on aspects outside the enterprise, believing opportunities are derived from external sources, including access to finance, government support, the identification of underlying information, technology trends, etc. External integration consists of the interaction between the identification of external resources and the discovery of opportunities. However, internal and external integration have their own limitations. In internal integration, piecing together resources will lead to opportunity limitations and detachment from reality, although it can break through the restrictions of resource constraints. Internal integration needs external integration to compensate for shortages. In external integration, enterprises identify external resources to discover and exploit potential opportunities by acquiring resources. The results deepen the understanding of different entrepreneurial strategic directions for subsequent research.

Third, the findings show that positive emotion and interpersonal relationship regulation further maximize the performance associated with internal and external integration. In a transitional economy, start-ups must flexibly utilize internal and external integration. In the integration process, leaders should focus not only on overcoming the uncertainty created by the environment but also on coordinating the team relationship and members' emotions to make the entrepreneurial activities proceed smoothly. Interpersonal emotion regulation is an important psychological function in social behavior that aims to stimulate, change, or regulate the emotions of others, such as organization members. However, this function is still poorly explored in organizational contexts, so our article aims to gain insights into how the interpersonal emotion regulation can be a 
TABLE 4 | Results of the relationship between IOR, interpersonal emotion regulation and entrepreneurial performance.

\begin{tabular}{|c|c|c|c|c|c|c|c|c|c|}
\hline & \multicolumn{8}{|c|}{ Dependent variable: Entrepreneurial performance } & \multirow[t]{3}{*}{ Results } \\
\hline & \multirow[b]{2}{*}{ Model 1} & \multicolumn{2}{|c|}{ Profitability } & \multirow[b]{2}{*}{ Model 4} & \multicolumn{4}{|c|}{ Growth } & \\
\hline & & Model 2 & Model 3 & & Model 1 & Model 2 & Model 3 & Model 4 & \\
\hline \multicolumn{10}{|l|}{ Control paths } \\
\hline $\begin{array}{l}\text { Enterprise size } \\
\text { Year established } \\
\text { Industry } \\
\text { Sales performance } \\
\text { Respondents' posts }\end{array}$ & $\begin{array}{c}0.119^{\star} \\
-0.026 \\
-0.027 \\
0.091^{\star} \\
-0.096\end{array}$ & $\begin{array}{l}0.056 \\
0.041 \\
0.022^{\star} \\
0.012 \\
0.033\end{array}$ & $\begin{array}{r}0.048 \\
0.034 \\
0.017 \\
0.010 \\
-0.000\end{array}$ & $\begin{array}{r}0.059 \\
0.008 \\
0.009 \\
0.005 \\
-0.017\end{array}$ & $\begin{array}{c}0.110^{\star} \\
-0.099^{\star} \\
-0.031 \\
0.107^{\star \star} \\
-0.086\end{array}$ & $\begin{array}{r}0.056 \\
-0.028 \\
0.015 \\
0.018 \\
0.044\end{array}$ & $\begin{array}{r}0.044 \\
-0.033 \\
0.011 \\
0.019 \\
0.018\end{array}$ & $\begin{array}{r}0.048 \\
-0.064^{*} \\
0.004 \\
0.020 \\
0.001\end{array}$ & \\
\hline \multicolumn{10}{|l|}{ Main effect paths } \\
\hline $\begin{array}{l}\text { Internal integration } \\
\text { External integration } \\
\text { Positive emotion regulation } \\
\text { Interpersonal relationship regulation }\end{array}$ & & $\begin{array}{l}0.588^{\star \star} \\
0.238^{\star \star \star} \\
-0.170^{\star \star \star} \\
-0.059\end{array}$ & $\begin{array}{l}0.484^{\star \star \star} \\
0.250^{\star \star \star} \\
-0.115^{\star \star} \\
-0.012\end{array}$ & $\begin{array}{l}0.332^{\star \star \star} \\
0.307^{\star \star \star} \\
-0.112^{\star \star} \\
0.012\end{array}$ & & $\begin{array}{l}0.522^{\star \star \star} \\
0.329^{\star \star \star} \\
-0.073 \\
-0.069\end{array}$ & $\begin{array}{l}0.442^{\star \star \star} \\
0.365^{\star \star \star} \\
-0.043 \\
-0.048\end{array}$ & $\begin{array}{c}0.277^{\star \star \star} \\
0.430^{\star \star \star} \\
-0.101^{\star} \\
0.022\end{array}$ & \\
\hline \multicolumn{10}{|l|}{ Two-way interaction paths } \\
\hline $\begin{array}{l}\text { Positive emotion regulation } \times \text { interpersonal } \\
\text { relationship regulation }\end{array}$ & & & 0.061 & $0.118^{\star \star \star}$ & & & 0.033 & $0.101^{\star \star}$ & \\
\hline $\begin{array}{l}\text { Internal integration } \times \text { positive emotion } \\
\text { regulation }\end{array}$ & & & $0.160^{\star \star \star}$ & 0.060 & & & $0.213^{\star \star \star}$ & 0.076 & \\
\hline $\begin{array}{l}\text { Internal integration } \times \text { interpersonal relationship } \\
\text { regulation }\end{array}$ & & & -0.047 & -0.095 & & & -0.078 & $-0.142^{\star \star}$ & \\
\hline $\begin{array}{l}\text { External integration } \times \text { positive emotion } \\
\text { regulation }\end{array}$ & & & $-0.173^{\star \star \star}$ & $-0.180^{\star \star \star}$ & & & $-0.224^{\star \star \star}$ & $-0.214^{\star \star \star}$ & \\
\hline $\begin{array}{l}\text { External integration } \times \text { interpersonal relationship } \\
\text { regulation }\end{array}$ & & & -0.036 & -0.034 & & & 0.057 & 0.047 & \\
\hline \multicolumn{10}{|l|}{ Hypothesized paths } \\
\hline $\mathrm{H} 1$ : Internal integration & & & & $0.332^{\star \star \star}$ & & & & $0.277^{\star \star \star}$ & Support \\
\hline H2: External integration & & & & $0.307^{\star \star \star}$ & & & & $0.430^{\star \star \star}$ & Support \\
\hline H3: Internal integration $\times$ external integration & & & & $0.149^{\star \star \star}$ & & & & $0.160^{\star \star \star}$ & Support \\
\hline $\begin{array}{l}\mathrm{H} 4 \text { : Internal integration } \times \text { external integration } \times \\
\text { positive emotion regulation }\end{array}$ & & & & $0.063^{\star \star}$ & & & & $0.139^{\star \star \star}$ & Support \\
\hline $\begin{array}{l}\text { H5: Internal integration } \times \text { external integration } \\
\text { xinterpersonal relationship regulation }\end{array}$ & & & & $0.096^{\star \star \star}$ & & & & $0.068^{\star \star}$ & Support \\
\hline $\mathrm{N}$ & 274 & 274 & 274 & 274 & 274 & 274 & 274 & 274 & \\
\hline $\mathrm{R}^{2}$ & 0.139 & 0.669 & 0.696 & 0.737 & 0.115 & 0.619 & 0.643 & 0.701 & \\
\hline Adjusted $\mathrm{R}^{2}$ & 0.123 & 0.658 & 0.679 & 0.719 & 0.098 & 0.606 & 0.623 & 0.682 & \\
\hline$\triangle R^{2}$ & - & 0.535 & 0.021 & 0.040 & - & 0.508 & 0.017 & 0.059 & \\
\hline$F$ value & 8.707 & 59.541 & 42.419 & 42.220 & 6.967 & 47.847 & 33.342 & 35.461 & \\
\hline
\end{tabular}

${ }^{*} p<0.10 ;{ }^{* *} p<0.05 ;{ }^{* *} p<0.01$.

tool for leaders to influence performance in the context of internal and external integration in organizations. This effort is consistent with previous work on the role of emotional regulation in leadership and organizations (Riggio and Reichard, 2008; Madrid et al., 2019; Torrence and Connelly, 2019), expanding the application of basic psychology in the organizational field (Gross, 2013; Niven, 2017). The level of interpersonal emotion regulation becomes essential for explaining the relationship between strategy orientation and performance.

\section{Managerial Implications}

First, this paper explores the synergy and relationship between opportunities and resources. Doing so provides a clear solution for start-ups on how to coordinate opportunities and resources in a dynamic environment, which is critical to improving corporate performance. Firms identifying opportunities in the market will inevitably be followed by a multitude of competitors, which will decrease the value of opportunities and make market competition increasingly fierce. Hence, a shortage of resources will again be an enterprise limitation; however, internal integration will be helpful in solving this problem. External integration needs internal integration to compensate for the shortage of resources caused by fierce market competition. In summary, the IOR represents a high level of integration between internal and external integration, each of which can compensate for the other's deficiencies to achieve high enterprise performance in a transitional economy. Therefore, in transitional economic environments, the strategic positioning and implementation must be carried out from the internal and external aspects of the enterprise, and companies need to coordinate and use different strategies and capabilities, such as internal and external integration. Different entrepreneurial strategies should not be regarded as contrary but as complementary.

Second, the results show that interpersonal emotion regulation plays an important role in the relationship between 


\section{(A) IOR, Internal integration, external integration and entrepreneurial performance}

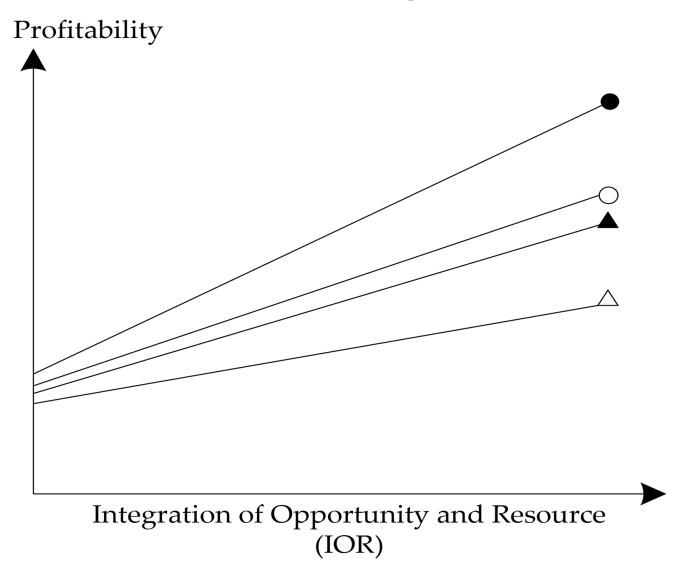

- High internal integration, High external integration

- Low internal integration, High external integration
Growth

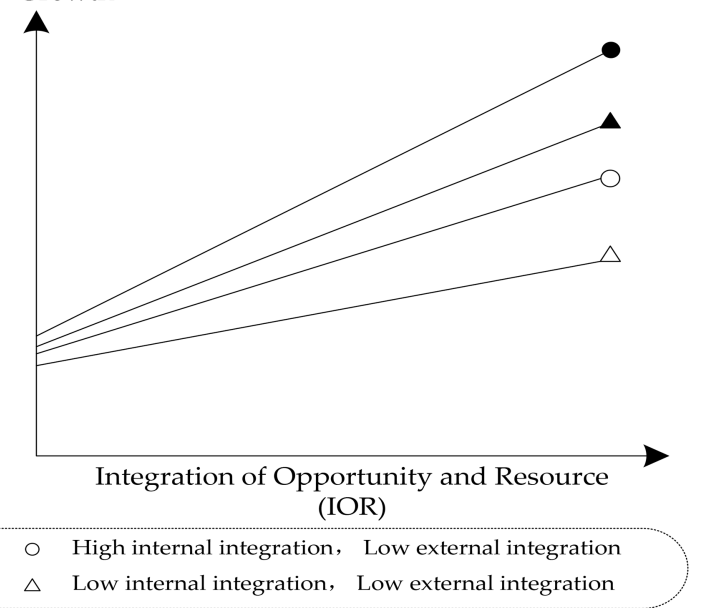

(B) IOR, interpersonal emotion regulation and entrepreneurial performance

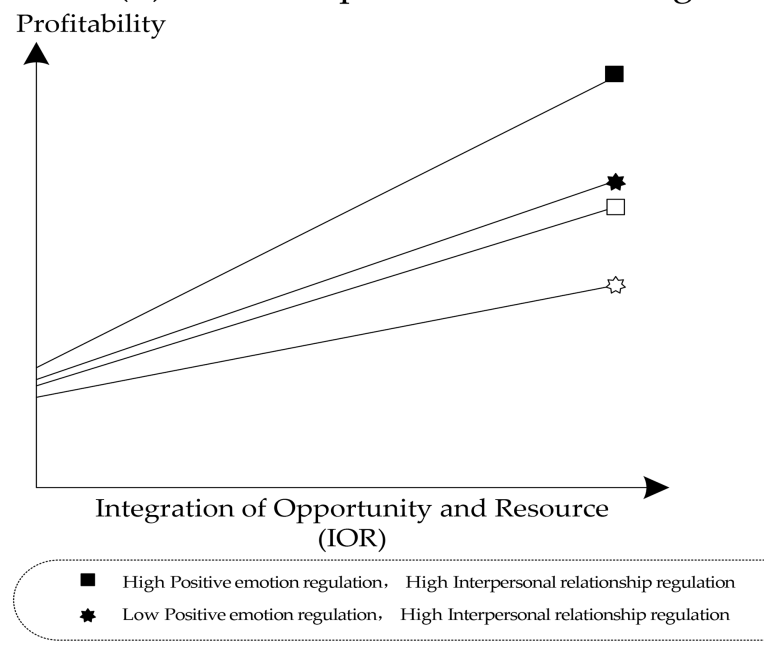

Growth

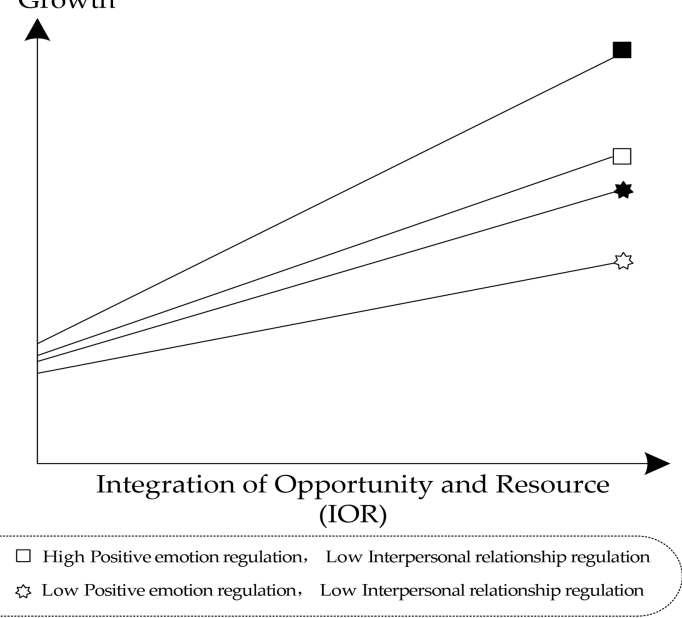

FIGURE 3 | Plots of the interaction effects.

the IOR and entrepreneurial performance, this conclusion provides more comprehensive guidance for managers to predict and influence employee behavior. Start-ups need to effectively regulate interpersonal emotion in a turbulent system and dynamic competitive market to achieve higher returns. Therefore, entrepreneurs should first realize that interpersonal emotional regulation plays an important role. And then we encourage start-ups to engage in interpersonal emotion regulation activities. This step requires enterprises to pay attention to the training of identifying leaders' tendencies and abilities in interpersonal emotion regulation from the perspective of leaders' development plans and to improve and construct enterprise effective strategies. Specifically, a leader's development plan should include assessment and training of interpersonal emotional regulation and emotional intelligence skills, for example, through role-playing and simulation. Alternatively, when recruiting candidates for team leadership positions, the personnel selection system could use interpersonal emotional regulation as an evaluation variable.

\section{Research Limitations and Future Research Directions}

The paper has two limitations. First, our data source is singular, and the transitional economy in China is unique. Other developing countries may have more diverse background elements. For example, cultural factors in different countries (such as collectivism and performance orientation) and informal institutional constraints (such as levels of political steadiness, putrefaction, judicial fairness, availability of education, and other common resources) may have different effects on strategic directions and business success. Future research should augment this area. Second, we selected entrepreneurial companies established within the last 8 years as the sample to ensure the consistency of the data. However, IOR and interpersonal emotion 
regulation are not negligible for mature enterprises. Therefore, studying the relationships among variables with combined life cycles can lead to conclusions that are more universal.

In addition, the results are consistent with institutional principles. The results emphasize that interpersonal emotion regulation (the core element in the development of a transitional economy in China) helps firms to effectively collect knowledge, acquire imperative channels, and develop new business networks under information asymmetries. Finally, this study suggests that entrepreneurial companies in transitional economic contexts should have stronger capabilities to develop the IOR and conduct interpersonal emotion regulation activities. However, the acquisition of these strategic capabilities is not simple but expends countless time and manifold resources. Therefore, follow-up research should help companies overcome these barriers, including through the construction of government protection agencies to enable start-ups to implement the best entrepreneurial practices in the commercial market group.

\section{DATA AVAILABILITY STATEMENT}

The raw data supporting the conclusions of this article will be made available by the authors, without undue reservation.

\section{REFERENCES}

Alvarez, S. A., and Busenitz, L. W. (2001). The entrepreneurship of resourcebased theory. J. Manag. 27, 755-775. doi: 10.1177/014920630102700609

Baker, T., and Nelson, R. (2005). Creating something from nothing: resource construction through entrepreneurial bricolage. Adm. Sci. Q. 50, 329-366. doi: 10.2189 /asqu.2005.50.3.329

Bakker, R. M., and Shepherd, D. A. (2017). Pull the plug or take the plunge: multiple opportunities and the speed of venturing decisions in the Australian mining industry. Acad. Manag. J. 60, 130-155. doi: 10.5465/amj.2013.1165

Baron, R. A. (2006). Opportunity recognition as pattern recognition: how entrepreneurs 'connect the dots' to identify new business opportunities. Acad. Manag. Perspect. 20, 104-119. doi: 10.5465/amp.2006.19873412

Bhuian, S. N., Menguc, B., and Bell, S. J. (2005). Just entrepreneurial enough: the moderating effect of entrepreneurship on the relationship between market orientation and performance. J. Bus. Res. 58, 9-17. doi: 10.1016/S0148-2963(03)00074-2

Boso, N., Story, V. M., and Cadogan, J. W. (2013). Entrepreneurial orientation, market orientation, network ties, and performance: study of entrepreneurial firms in a developing economy. J. Bus. Ventur. 28, 708-727. doi: 10.1016/j. jbusvent.2013.04.001

Brown, T. E., Davidsson, P., and Wiklund, J. (2001). An operationalization of Stevenson's conceptualization of entrepreneurship as opportunity-based firm behavior. Strateg. Manag. J. 22, 953-968. doi: 10.1002/smj.190

Casson, M., and Wadeson, N. (2007). The discovery of opportunities: extending the economic theory of the entrepreneur. Small Bus. Econ. 28, 285-300. doi: 10.1007/s11187-006-9037-7

Cheng, C. C. J., and Huizingh, E. K. R. E. (2014). When is open innovation beneficial? The role of strategic orientation. J. Prod. Innov. Manag. 31, 1235-1253. doi: 10.1111/jpim.12148

Davcik, N. S., and Sharma, P. (2016). Marketing resources, performance, and competitive advantage: a review and future research directions. J. Bus. Res. 69, 5547-5552. doi: 10.1016/j.jbusres.2016.04.169

Ennen, E., and Richter, A. (2010). The whole is more than the sum of its parts-or is it? A review of the empirical literature on complementarities in organizations. J. Manag. 36, 207-233. doi: 10.1177/0149206309350083

Fredrickson, B. L. (2001). The role of positive emotions in positive psychology: the broaden-and-build theory of positive emotions. Am. Psychol. 56, 218-226. doi: $10.1037 / 0003-066$ X.56.3.218

\section{ETHICS STATEMENT}

Ethical review and approval was not required for the study on human participants in accordance with the local legislation and institutional requirements. Written informed consent for participation was not required for this study in accordance with the national legislation and the institutional requirements.

\section{AUTHOR CONTRIBUTIONS}

NL and YS: writing. DJ: processing data. XY: revising. All authors contributed to the article and approved the submitted version.

\section{FUNDING}

This work was supported by the Jilin Province Social Science Foundation Project (2020C054) and Guangxi Science and Technology Plan Project (Guangxi Science and Technology Base and Talent Special Project: AD20159069).

Fredrickson, B. L., and Branigan, C. (2005). Positive emotions broaden the scope of attention and thought-action repertoires. Cognit. Emot. 19, 313-332. doi: 10.1080/02699930441000238

Friedman, R. S., and Forster, J. (2010). Implicit affective cues and attentional tuning: An integrative review. Psychol. Bull. 136, 875-893. doi: 10.1037/ a0020495

Fuller, C. M., Simmering, M. J., Atnic, G., Atinc, Y., and Babin, B. J. (2016). Common methods variance detection in business research. J. Bus. Res. 69, 3192-3198. doi: 10.1016/j.jbusres.2015.12.008

Gao, Y., Ge, B. S., Lang, X. X., and Xu, X. B. (2018). Impacts of proactive orientation and entrepreneurial strategy on entrepreneurial performance: an empirical research. Technol. Forecast. Soc. Chang. 135, 178-187. doi: 10.1016/j. techfore.2017.11.019

Ge, B. S., Sun, Y. Q., Chen, Y., and Gao, Y. (2016). Opportunity exploitation and resource exploitation: an integrative growth model for entrepreneurship. Internet Res. 26, 498-528. doi: 10.1108/IntR-04-2015-0123

Ge, B. S., Yang, Y. B., Jiang, D. K., Gao, Y., Du, X. M., and Zhou, T. T. (2018). An empirical study on green innovation strategy and sustainable competitive advantages: path and boundary. Sustain. For. 10:3631. doi: 10.3390/su10103631

Gross, J. J. (2013). Emotion regulation: taking stock and moving forward. Emotion 13, 359-365. doi: 10.1037/a0032135

Hitt, M.A., Ireland, R.D., and Hoskisson, R.E. (2003). Strategic Management: Competitiveness and Globalization (5th Edn.). Cincinnati, OH: Southwestern College Publishing Company.

Holman, D., and Niven, K. (2019). Does interpersonal affect regulation influence others' task performance? The mediating role of positive mood. Eur. J. Work Organ. Psychol. 28, 820-830. doi: 10.1080/1359432X.2019.1666105

Huang, T., Wu, F., Yu, J., and Zhang, B. (2015). Political risk and dividend policy: evidence from international political crises. J. Int. Bus. Stud. 46, 574-595. doi: $10.1057 /$ jibs.2015.2

Hulsheger, U., Anderson, N. R., and Salgado, J. (2009). Team-level predictors of innovation at work: a comprehensive meta-analysis spanning three decades of research. J. Appl. Psychol. 94, 1128-1145. doi: 10.1037/a0015978

Huy, Q. N. (1999). Emotional capability, emotional intelligence, and radical change. Acad. Manag. Rev. 24, 325-345. doi: 10.5465/amr.1999.1893939

Isen, A. M. (2000). "Positive affect and decision making," in Hand-Book of Emotions, Vol. 40. eds. M. Lewis, J. M. Haviland and L. F. Barrett (Guilford Press), 417-435. 
Keltner, D., and Haidt, J. (1999). Social functions of emotions at four levels of analysis. Cognit. Emot. 13, 505-521. doi: 10.1080/026999399379168

Knight, A. P., and Eisenkraft, N. (2015). Positive is usually good, negative is not always bad: The effects of group effect on social integration and task performance. J. Appl. Psychol. 100, 1214-1227. doi: 10.1037/apl0000006

Konradt, U., Filip, R., and Hoffmann, S. (2003). Flow experience and positive affect during hypermedia learning. Br. J. Educ. Technol. 34, 309-327. doi: $10.1111 / 1467-8535.00329$

Langfred, C. W. (2007). The downside of self-management: a longitudinal study of the effects of conflict on trust, autonomy, and task interdependence in self-managing teams. Acad. Manag. J. 50, 885-900. doi: 10.5465/ amj.2007.26279196

Li, P. P. (2012). Toward an integrative framework of indigenous research: the geocentric implications of yin-Yang balance. Asia Pac. J. Manag. 29, 849-872. doi: $10.1007 / \mathrm{s} 10490-011-9250-\mathrm{z}$

Little, L. M., Kluemper, D., Nelson, D. L., and Gooty, J. (2012). Development and validation of the interpersonal emotion management scale. J. Occup. Organ. Psychol. 85, 407-420. doi: 10.1111/j.2044-8325.2011.02042.x

Lumpkin, G. T., and Dess, G. G. (1996). Clarifying the entrepreneurial orientation construct and linking it to performance. Acad. Manag. Rev. 21, 135-172. doi: $10.5465 / \mathrm{amr} .1996 .9602161568$

Ma, R., and Huang, Y. C. (2016). Opportunity-based strategic orientation, knowledge acquisition, and entrepreneurial alertness: the perspective of the global sourcing suppliers in China. J. Small Bus. Manag. 54, 953-972. doi: $10.1111 /$ jsbm. 12222

Madrid, H. P., Peter, T., Karen, N., and Vasquez, C. A. (2019). Leader interpersonal emotion regulation and innovation in teams. Eur. J. Work Organ. Psychol. 11, 1-15. doi: $10.1111 /$ joop. 12292

Niven, K. (2016). Why do people engage in interpersonal emotion regulation at work? Organ. Psychol. Rev. 6, 305-323. doi: 10.1177/2041386615612544

Niven, K. (2017). The four key characteristics of interpersonal emotion regulation. Curr. Opin. Psychol. 17, 89-93. doi: 10.1016/j.copsyc.2017.06.015

Niven, K., Holman, D., and Totterdell, P. (2012). How to win friendship and trust by influencing people's feelings: An investigation of interpersonal affect regulation and the quality of relationships. Hum. Relat. 65, 777-805. doi: $10.1177 / 0018726712439909$

Niven, K., Totterdell, P., and Holman, D. (2009). A classification of controlled interpersonal affect regulation strategies. Emotion 9, 498-509. doi: 10.1037/ a0015962

Petti, C., and Zhang, S. (2011). Factors influencing technological entrepreneurship capabilities: towards an integrated research framework for Chinese enterprises. J. Technol. Manag. Chin. 6, 7-25. doi: 10.1108/17468771111105631

Podsakoff, P., MacKenzie, S. B., Lee, J. Y., and Podsakoff, N. P. (2003). Common method biases in behavioral research: a critical review of the literature and recommended remedies. J. Appl. Psychol. 88, 879-903. doi: 10.1037/0021-9010.88.5.879

Riggio, R. E., and Reichard, R. J. (2008). The emotional and social intelligences of effective leadership: an emotional and social skill approach. J. Manag. Psychol. 23, 169-185. doi: 10.1108/02683940810850808

Rothbard, N. P., and Wilk, S. L. (2011). Waking up on the right or wrong side of the bed: start-of-workday mood, work events, employee affect, and performance. Acad. Manag. J. 54, 959-980. doi: 10.5465/amj.2007.0056

Samuelsson, M., and Davidsson, P. (2009). Does venture opportunity variation matter? Investigating a systematic process differences between innovative and imitative new ventures. Small Bus. Econ. 33, 229-255. doi: 10.1007/ s11187-007-9093-7

Sarasvathy, S. D. (2009). Effectuation: Elements of Entrepreneurial Expertise. Cheltenham, UK: Edward Elgar Publishing.

Senyard, J., Baker, T., and Davidsson, P. (2009). Entrepreneurial bricolage: towards systematic empirical testing. Front. Entrep. Res. 29, 1-14.
Shane, S., and Venkataraman, S. (2000). The promise of entrepreneurship as a field of research. Acad. Manag. Rev. 25, 217-226. doi: 10.2307/259271

Shepherd, D. A., and Detienne, D. R. (2005). Prior knowledge, potential financial reward, and opportunity identification. Entrep. Theory Pract. 29, 91-112. doi: $10.1111 /$ j.1540-6520.2005.00071.x

Sirmon, D. G., Hitt, M. A., Ireland, R. D., and Gilbert, B. A. (2011). Resource orchestration to create competitive advantage: breadth, depth, and life cycle effects. J. Manag. 37, 1390-1412. doi: 10.1177/0149206310385695

Song, M., Droge, C., and Calantone, H. R. (2010). Marketing and technology resource complementarity: an analysis of their interaction effect in two environmental contexts. Strateg. Manag. J. 26, 259-276. doi: 10.1002/smj.450

Tan, J. (2001). Innovation and risk-taking in a transitional economy: A comparative study of Chinese managers and entrepreneurs. J. Bus. Ventur. 16, 359-376. doi: 10.1016/S0883-9026(99)00056-7

Teece, D. G. (2007). Explicating dynamic capabilities: The nature and micro foundations of (sustainable) enterprise performance. Strateg. Manag. J. 28, 1319-1350. doi: $10.1002 / \mathrm{smj} .640$

Timmons, J.A., Spinelli, S., and Tan, Y. (1994). New Venture Creation: Entrepreneurship for the 21st Century. Burr Ridge, IL: Irwin.

Torrence, B. S., and Connelly, S. (2019). Emotion regulation tendencies and leadership performance: an examination of cognitive and behavioral regulation strategies. Front. Psychol. 10:1486. doi: 10.3389/fpsyg.2019.01486

Walder, A. G. (1995). Local governments as industrial firms: an organizational analysis of China's transitional economy. Am. J. Sociol. 101, 263-301. doi: $10.1086 / 230725$

West, M. A. (2002). Sparkling fountains or stagnant ponds: An integrative model of creativity and innovation implementation in work groups. Appl. Psychol. Int. Rev. 51, 355-387. doi: 10.1111/1464-0597.00951

Wiklund, J., and Shepherd, D. (2003). Research notes and commentaries: knowledge-based resources, entrepreneurial orientation, and the performance of small and medium-sized businesses. Strateg. Manag. J. 24, 1307-1314. doi: $10.1002 / \mathrm{smj} .360$

Williams, L. J., and McGonagle, A. K. (2016). Four research design and a comprehensive analysis strategy for investigating common method variance with self-reported measures using latent variable. J. Bus. Psychol. 31, 339-359. doi: 10.1007/s10869-015-9422-9

Zahra, S. A. (2012). Organizational learning and entrepreneurship in family firms: exploring the moderating effect of ownership and cohesion. Small Bus. Econ. 38, 51-65. doi: 10.1007/s11187-010-9266-7

Zahra, S. A., Korri, J. S., and Yu, J. F. (2005). Cognition and international entrepreneurship: implications for research on international opportunity recognition and interpersonal relationship regulation. Int. Bus. Rev. 14, 129-146. doi: 10.1016/j.ibusrev.2004.04.005

Conflict of Interest: The authors declare that the research was conducted in the absence of any commercial or financial relationships that could be construed as a potential conflict of interest.

Publisher's Note: All claims expressed in this article are solely those of the authors and do not necessarily represent those of their affiliated organizations, or those of the publisher, the editors and the reviewers. Any product that may be evaluated in this article, or claim that may be made by its manufacturer, is not guaranteed or endorsed by the publisher.

Copyright (c) 2021 Li, Sun, Jiang and Yang. This is an open-access article distributed under the terms of the Creative Commons Attribution License (CC BY). The use, distribution or reproduction in other forums is permitted, provided the original author(s) and the copyright owner(s) are credited and that the original publication in this journal is cited, in accordance with accepted academic practice. No use, distribution or reproduction is permitted which does not comply with these terms. 